\title{
The Electron Centenary: Cavendish Laboratory Lecture Series
}

On 13th., 14th. and 21st. March Trinity College and the Cavendish Laboratory Cambridge, UK, celebrated the centenary of the discovery of the electron in 1897 by J.J. Thomson, Cavendish Professor from 1884 to 1919 and then Master of Trinity College, Cambridge. The celebration took the form of a series of lectures held at the Cavendish by distinguished international speakers. The programme for the first two days (during the full term period, so that undergraduates could attend) was sponsored by Trinity College, with the organisation in the competent hands of Dr. Gordon Squires. The final day's speakers had been invited by the Physics Department, the arrangements made by Prof. A. Howie. The audience at both series of lectures was an invited one, a veritable spectrum of celebrated personalities from the academic sector in the UK and abroad attending, as well as physicists, engineers and other scientists from industry and the government. Several Nobel laureates were sighted.

Timing of the lectures was such that there was ample opportunity to visit the Cavendish museum, with a special display honouring J.J. Thomson, and to look into the laboratories at ongoing Cavendish work on the electron. This really meant visiting almost any laboratory because the electron is literally everywhere: high energy physics; radio astronomy; semiconductor physics; microelectronics; optoelectronics; heavy electrons; superconductivity; electronic structure theory of solids and molecules; and electron microscopy. The lecture programmes were as follows: March 13

Introduction - Prof. Archie Howie, and Sir Michael Atiyah;

J.J. Thomson and the Discovery of the Electron - Dr. Gordon Squires, University of Cambridge.

Recollections of J.J. Thomson -

Prof. Samuel Devons, Columbia

University, New York City.

Does the Charge of the Electron Stay

Constant as the Universe Evolves? -

Prof. Freeman Dyson, Institute for
Advanced Study, Princeton.

What is Chemistry? 100 Years After

J.J. Thomson's Discovery - Prof. Ahmed

Zewail, California Institute of Technology.

March 14

The Electron in Photosynthesis -

Lord Porter, Imperial College, London.

Electrons and Positrons in Medical

Imaging - Prof. Laurie Hall, University of Cambridge.

The Microelectronic Revolution -

Prof. Alec Broers, Vice-Chancellor,

University of Cambridge.

March 21

J.J. Thomson and the Discovery of the

Electron - Dr. G. Squires.

The Electron as a Fundamental Particle -

Prof. C. Llewellyn-Smith, CERN.

Pulsar Radiation Mechanisms - Prof. A.

Hewish, Cavendish Laboratory,

Cambridge.

From Ceramics to SQUIDS: a Tale of Two

Electrons - Prof. J. Clarke, Berkeley.

Electron Transfers in Chemistry and

Biology - Prof. R. Marcus, Cal. Tech.

Quantum Dots and Single Electron

Effects - Prof. K. von Klitzing, MPI

Stuttgart.

The Electron Microscope in Structural

Biology - Sir Aaron Klug, President of the Royal Society, University of Cambridge.

Scanning Tunneling Microscopy - a

Tool with and for Electrons - Dr. H. Rohrer, IBM Zurich.

Electron Holography - Dr. A. Tonomura, Hitachi.

Microelectronics Industrial Fabrication Dr. G. Moore, Intel.

This list of lecture titles alone shows the impact the discovery of the first subatomic particle has had on modern science, technology and society. Thomson gave the twentieth century not just atomic and quantum physics, but modern electronics - practically every device we depend on in our daily lives! He heralded the information revolution and the global village; science without the electron, technology and business without electronics? - inconceivable!

The discovery of the electron was based upon the understanding of the particle in its simplest possible context in vacuo - rather than in its normal setting within atoms, molecules and bulk matter. Unsurprisingly, therefore, the first applications of the new knowledge during the first half of this century were concerned with electrons in vacuum: vacuum tubes and cathode-ray oscilloscopes.

In England in the 1870 s and 1880 s interest in cathode-ray phenomena had been stirred by the spectacular demonstrations of William Crookes. His "Crookes' tubes" (see front cover illustration) displayed the magic of gas discharges in luminous striations, sinuous glows, scintillations and phosphorescences - all forerunners of our neon tubes and colour TVs. The popularisation of the mystique and imagery of cathode rays contributed to the growing debate over their nature. In 1893 J.J. Thomson surveyed the complex gas-discharge process as follows: "The phenomena attending the electric discharge through gases are so beautiful and varied that they have attracted the attention of numerous observers. The attention given to these phenomena is not, however, due so much to the beauty of the experiments, as to the widespread conviction that there is perhaps no other branch of physics which affords us so promising an opportunity of penetrating the secret of electricity."

In this era where it has become all too fashionable to dismiss pure research as irrelevant to future real world needs, to look back on the last 100 years of physics achievement alone is a humbling reminder of the evolutionary influence on mankind of fundamental research. Carried out with modest means by today's standards, towards the end of the Victorian era, how can we not appreciate the research that is leading us inexorably towards continuing miniaturisation - to wristwatch-phones, wallet-computers and flat-screen televisions?

It is our hope that with a century's understanding of this discovery and its overwhelming consequences, it might be possible to incite general interest for instead of inadequate understanding of science; to induce strategic vision of research rather than shortsightedness in its financial planning. And, finally, we must never cease in our efforts to ensure that future generations are given the freedom to realise and successfully exploit scientific revolutions. 